\title{
CLINICAL EPIDEMIOLOGY OF OSTEOPOROSIS AMONG ELDERLY FISHING AND AGRICULTURAL POPULATION IN TAIPEI, TAIWAN
}

Chin-Yu Lee ${ }^{1,2}$, Pei-En Chen ${ }^{3}$, Tao-Hsin Tung ${ }^{4}$

${ }^{1}$ Hechi Third People's Hospital, Guangxi, China

${ }^{2}$ School of Medicine, College of Medicine, Fu Jen Catholic University, New Taipei, Taiwan

${ }^{3}$ Taiwan Association of Health Industry Management and Development, Taipei, Taiwan

${ }^{4}$ Department of Medical Research and Education, Cheng Hsin General Hospital, Taipei, Taiwan

Corresponding Author: Prof. Tao-Hsin Tung: ch2876@chgh.org.tw

Submitted: 19 June 2019. Accepted: 22 January 2020. Published: 19 March 2020.

\begin{abstract}
\section{Purpose}

This article is aimed to evaluate through quantification the prevalence and related aspects of osteoporosis among the aging people working in the fishing and agricultural areas in Taipei, Taiwan.

\section{Methods}

The population $(n=4360)$ aged 65 years and above and who were admitted to a teaching hospital for a physical examination in 2010 were involved in this study. Osteoporosis is defined as bone mineral density (BMD) of 2.5 standard deviation (SD) or more under the young adult mean value $(-2.5 \mathrm{SD}$ or inferior).

\section{Results}

The population presented an over-occurrence of osteoporosis, scoring $34.4 \%$, and exposed a statistically important rise with cumulative age $(\mathrm{P}<0.001)$. Female population displayed a higher incidence than male population $(48.1 \%$ vs. $26.4 \%$; $<<0.001)$. The age-specific frequency of osteoporosis in 65-74 years, $75-84$ years, and $\geq 85$ years was $27.7,40.0$, and $56.7 \%$, respectively. The multinomial logistic regression showed that age (odds ratio $[\mathrm{OR}]=1.07,95 \%$ confidence interval $[\mathrm{CI}]: 1.06-1.09$ ), body height $(\mathrm{OR}=0.98,95 \% \mathrm{CI}: 0.97-0.99)$, body weight $(\mathrm{OR}=0.97,95 \% \mathrm{CI}: 0.95-099)$, waist circumference $(\mathrm{OR}=1.02,95 \% \mathrm{CI}: 1.00-1.03)$, total cholesterol $(\mathrm{OR}=1.01,95 \% \mathrm{CI}: 1.00-1.02)$, uric acid $(\mathrm{OR}=0.90$, 95\% CI: 0.85-0.95), and regular habits of meat intake (OR=1.47, 95\% CI:1.19-1.75) were statistically significantly associated with osteoporosis.
\end{abstract}




\section{Conclusion}

Numerous medical aspects were individualistically specified, relating the occurrence of osteoporosis in the elderly among the population involved in fishing and agriculture.

Key Words: agricultural and fishing population; elderly; osteoporosis; prevalence

\section{INTRODUCTION}

Nowadays, osteoporosis is one of the most common diseases among the elderly worldwide. ${ }^{1}$ People with osteoporosis may not be aware that their bones are getting weaker since it is a silent disease. $^{2}$ Not until the patients suffer from fractures in their hips, spines, wrists, or other bones do they know that their own health condition is deteriorating. ${ }^{3}$ Patients with osteoporosis not only face painful experiences but also have greater risk of serious disability or even death. ${ }^{4}$ In addition, the clinical care of this chronic disease costs lots of money, efforts, and medical resources. ${ }^{5}$ As the number of elderly population grows continuously, osteoporosis may cause an increasing burden on society and healthcare systems. Therefore, it is important to have appropriate strategies to assess the state of health.

Osteoporosis is determined by several risk factors. Higher blood glucose concentration is one of the common symptoms of osteoporosis among female patients. ${ }^{6,7}$ Previous studies also indicated a positive relationship between higher uric acid levels and higher spine bone mineral density (BMD) in men and in peri- and postmenopausal women. ${ }^{8,9}$ Low body weight is considered as another important risk factor for osteoporosis in healthy 40-60-year-old women. ${ }^{10}$ In addition to some health conditions, daily intake habits and personal life style are also associated with the morbidity of osteoporosis. An intake of dairy products and fruits may decrease the risk of osteoporosis in postmenopausal women. ${ }^{11}$ Smoking also contributed to fracture among postmenopausal women. ${ }^{12}$

These consequences give us some indicators to evaluate the probability of suffering from fractures due to osteoporosis; however, most of these researches apply only to postmenopausal women. It is possible to observe from factors related to preventive medicine perspective; it is not only vital to be aware of the contextual morbidity of osteoporosis locally but also to sightsee the whole range of demographic and biological indicators that could be linked with osteoporosis.

Due to some ambiguity around the frequency and the related threat, aspects of osteoporosis expose gender dissimilarity among elderly work-related subjects. Therefore, to recognize the commonness of and related elements of osteoporosis, this research was conducted. In an effort to discover the potential for condition-related gender variance, it was measured such that dissimilarity might emphasize significant repercussions for comprehending the general pathogenesis of osteoporosis among the elderly agricultural and fishing population in Taipei, Taiwan.

\section{METHODS}

\section{Data Resource and Data Collection}

A total of 4360 healthy occupational adults in agricultural and fishing professional fields, aged 65 years and over, were involved in this cross-sectional study. They willingly assisted to one teaching hospital in Northern Taiwan for a yearly physical examination between January 1, 2010 and December 31, 2010. All actions and patients' data were accomplished in agreement with the procedures of the institutional ethics committee and followed the guidelines of the Declaration of Helsinki.

The medical histories and measurements of the participants were obtained by well-trained nurses. Personal and family histories of hypertension, 
type 2 diabetes, cardiovascular diseases, and other chronic diseases were obtained by a structured health interview questionnaire. The study participants were asked to take off the shoes and any other belongings that could possibly add extra weight when they were weighed. Body mass index (BMI) was evaluated according to heights and weights. In addition, the waist perimeter was stated at the level of the iliac procedures and the umbilicus with a lax tape quantity to guesstimate abdominal obesity.

For each person, blood pressure was measured twice in the sitting position, with an intermission of $15 \mathrm{~min}$ between the measurements, by the average earnings of sphygmomanometer of suitable measurement, after a break period for $30 \mathrm{~min}$. Patients undergoing antihypertensive therapy were examined to measure hypertension.

Fasting blood samples were strained via venipuncture from the study participants by medical nurses. Overnight-fasting serum and plasma samples (from whole blood preserved with Ethylenediaminetetraacetic acid (EDTA) and $\mathrm{NaF})$ were retained ice-covered $\left(-20^{\circ} \mathrm{C}\right)$ until they are prepared for examination. BMD was examined by dual energy X-ray absorptiometry (DXA). Osteopenia was defined as BMD being between 1 and 2.5 standard deviation (SD) below the young adult mean value. Likewise, osteoporosis was defined as BMD being 2.5 SD or more below the young adult mean value. ${ }^{13}$ Metabolic syndrome was identified according to The US National Cholesterol Education Programme Adult Treatment Panel III (NCEP ATP III) standards, that is, at least three of the subsequent five constraints should be extant: abdominal obesity (waist circumference $>90 \mathrm{~cm}$ for males), hypertension (systolic blood pressure [SBP] $>130 \mathrm{~mm} \mathrm{Hg}$ and/or diastolic blood pressure $[\mathrm{DBP}]>85 \mathrm{~mm} \mathrm{Hg}$ ) or history of antihypertensive practice, hypertriglyceridemia $(\geq 150 \mathrm{mg} /$ $\mathrm{dL}$ ) or incidence of action for this condition, low high density lipoprotein cholesterol
(HDL-C) $(<40 \mathrm{mg} / \mathrm{dL}$ in males) or existence of treatment for this condition, and high fasting plasma glucose $(>100 \mathrm{mg} / \mathrm{dL})$ or incidence of finding of type 2 diabetes. ${ }^{14,15}$

\section{Statistical Analysis}

Statistical analysis was achieved via SPSS for Windows (SPSS version 18.0; Chicago, IL, USA). One-way analysis of variance (ANOVA) system was approved to evaluate alterations in the mean rate of constant variables. The $\chi^{2}$-trend test was utilized to regulate important variances in quantities among definite variables. Multinomial logistic regression is the addition for the (binary) logistic deterioration when the categorical dependent outcome has more than two stages. ${ }^{16}$ This technique was also accomplished to deliver a number of measurements for each of the two contrasts of osteoporosis and to inspect the individuality of features related to the frequency of osteoporosis. A P-value of $<0.05$ was reflected to characterize a statistically noteworthy dissimilarity among the examined population.

\section{RESULTS}

Table 1 shows the sex- and age-specific prevalence of osteopenia and osteoporosis among the elderly study participants. The results indicated the prevalence of osteopenia and osteoporosis for the study population to be $37.8 \%$ and $34.4 \%$, respectively. Under the circumstance of osteoporosis, the prevalence for women proved to be higher than for men $(48.1 \%$ vs. $26.4 \%, \mathrm{P}<0.001$ for $\chi^{2}$ test). From the CochranArmitage trend test, the prevalence of osteoporosis showed a statistically significant increase with increasing subjects' age by means of the $\chi^{2}$ trend test $(\mathrm{P}<0.001)$.

Table 2 shows the demographic and biochemical features of the contributors who were and were not screened with abnormal BMD. In addition to age $(\mathrm{P}<0.001)$, height $(\mathrm{P}<0.001)$, weight $(\mathrm{P}<0.001)$, BMI $(\mathrm{P}<0.001)$, waist circumference 
TABLE 1 The Sex- and Age-Specific Prevalence of Osteoporosis among the Elderly Agricultural and Fishing Screened Subjects $(n=4360)$

\begin{tabular}{|c|c|c|c|c|c|c|c|}
\hline \multirow{4}{*}{ Variable } & \multicolumn{7}{|c|}{ Osteoporosis } \\
\hline & \multirow{3}{*}{$\begin{array}{c}\text { Total } \\
\text { Screened } \\
\text { No. }\end{array}$} & \multicolumn{2}{|c|}{ Subtotal } & \multicolumn{2}{|c|}{ Osteopenia } & \multicolumn{2}{|c|}{ Osteoporosis } \\
\hline & & \multicolumn{2}{|c|}{ Prevalence } & \multicolumn{2}{|c|}{ Prevalence } & \multicolumn{2}{|c|}{ Prevalence } \\
\hline & & No. & $(\%)$ & No. & $(\%)$ & No. & $(\%)$ \\
\hline \multicolumn{8}{|l|}{ Sex } \\
\hline Men & 2758 & 1804 & 65.4 & 1076 & 39.0 & 728 & 26.4 \\
\hline Women & 1602 & 1343 & 83.8 & 572 & 35.7 & 771 & 48.1 \\
\hline P-value for $\chi^{2}$-test & \multicolumn{7}{|c|}{$<0.001$} \\
\hline \multicolumn{8}{|l|}{ Age } \\
\hline $65-74$ & 2433 & 1639 & 67.4 & 964 & 39.6 & 675 & 27.7 \\
\hline $75-84$ & 1604 & 1229 & 76.6 & 588 & 36.7 & 641 & 40.0 \\
\hline$\geq 85$ & 323 & 279 & 86.4 & 96 & 29.7 & 183 & 56.7 \\
\hline P-value for Cochran-Armitage trend test & \multicolumn{7}{|c|}{$<0.001$} \\
\hline Total & 4360 & 3147 & 72.2 & 1648 & 37.8 & 1499 & 34.4 \\
\hline
\end{tabular}

TABLE 2 Comparisons of Demographic and Biochemical Characteristics of Osteoporosis among the Elderly Agricultural and Fishing Screened Population Subjects $(n=4360)$

\begin{tabular}{|l|c|c|c|c|c|}
\hline \multirow{2}{*}{ Variables } & General $(\mathbf{n}=\mathbf{4 3 6 0})$ & Normal & Osteopenia & Osteoprosis & $\begin{array}{c}\text { P-value } \\
\text { for F-test }\end{array}$ \\
\cline { 2 - 5 } & Mean \pm SD & Mean \pm SD & Mean \pm SD & Mean \pm SD & $<0.001$ \\
\hline Age $($ year $)$ & $74.38 \pm 6.60$ & $72.93 \pm 6.01$ & $73.92 \pm 6.30$ & $76.08 \pm 7.00$ & $<0.07 .001$ \\
\hline Height $(\mathrm{cm})$ & $156.99 \pm 8.49$ & $158.83 \pm 7.42$ & $157.41 \pm 8.20$ & $155.05 \pm 9.19$ & $<0.001$ \\
\hline Weight $(\mathrm{kg})$ & $62.00 \pm 10.83$ & $64.51 \pm 10.49$ & $62.28 \pm 10.52$ & $59.67 \pm 10.95$ & $<0.001$ \\
\hline BMI $\left(\mathrm{kg} / \mathrm{m}^{2}\right)$ & $25.19 \pm 3.76$ & $25.54 \pm 3.48$ & $25.14 \pm 3.60$ & $24.96 \pm 4.10$ & $<0.001$ \\
\hline Waist circumference $(\mathrm{cm})$ & $86.75 \pm 10.05$ & $88.06 \pm 9.76$ & $86.72 \pm 9.70$ & $85.71 \pm 10.52$ & $<0.001$ \\
\hline Blood sugar $(\mathrm{mg} / \mathrm{dL})$ & $100.56 \pm 27.80$ & $102.39 \pm 30.91$ & $100.35 \pm 27.45$ & $99.31 \pm 25.37$ & 0.02 \\
\hline SBP $(\mathrm{mm} \mathrm{Hg})$ & $137.48 \pm 22.34$ & $137.49 \pm 22.79$ & $137.08 \pm 22.02$ & $137.92 \pm 22.33$ & 0.57 \\
\hline DBP $(\mathrm{mm} \mathrm{Hg)}$ & $78.72 \pm 12.25$ & $79.53 \pm 12.12$ & $78.73 \pm 12.45$ & $78.05 \pm 12.09$ & 0.01 \\
\hline Total cholesterol $(\mathrm{mg} / \mathrm{dL})$ & $200.70 \pm 35.74$ & $197.76 \pm 34.33$ & $201.69 \pm 35.97$ & $201.98 \pm 36.49$ & 0.003 \\
\hline Triglycerides $(\mathrm{mg} / \mathrm{dL})$ & $132.07 \pm 86.10$ & $134.47 \pm 89.12$ & $134.02 \pm 94.87$ & $137.99 \pm 72.27$ & 0.08 \\
\hline HDL-C $(\mathrm{mg} / \mathrm{dL})$ & $54.15 \pm 15.05$ & $55.37 \pm 14.42$ & $54.15 \pm 15.06$ & $52.58 \pm 15.38$ & $<0.001$ \\
\hline Uric acid $(\mathrm{mg} / \mathrm{dL})$ & $6.12 \pm 1.56$ & $6.33 \pm 1.53$ & $6.10 \pm 1.52$ & $5.98 \pm 1.60$ & $<0.001$ \\
\hline
\end{tabular}

$B M I=$ body mass index DBP = diastolic blood pressure; HDL-C = high density lipoprotein cholesterol; $S B P=$ systolic blood pressure; $S D=$ standard deviation .

$(\mathrm{P}<0.001)$, blood sugar $(\mathrm{P}=0.02)$, DBP $(\mathrm{P}=0.01)$, total cholesterol $(\mathrm{P}=0.003)$, HDL-C $(\mathrm{P}<0.001)$, and uric acid $(\mathrm{P}<0.001)$ were significantly different between normal, osteopenia, and osteoporosis subgroups.
The effects of independent associated risk factors on osteopenia and osteoporosis were studied using the multinomial logistic regression system. As shown in Table 3, in addition to alteration of be wildering features, age 
TABLE 3 Multinomial Logistic Regression on the Risk Factors Associated with Osteoporosis Disease among the Elderly Fishing and Agricultural Population $(n=4360)$

\begin{tabular}{|c|c|c|c|}
\hline Variables & Odds ratio & 95\% Confidence interval & P-value \\
\hline \multicolumn{4}{|l|}{ Osteopenia versus normal } \\
\hline Age (year) & 1.03 & $1.01-1.04$ & $<0.001$ \\
\hline Height $(\mathrm{cm})$ & 1.00 & $0.98-1.01$ & 0.67 \\
\hline Weight $(\mathrm{kg})$ & 0.98 & $0.97-1.00$ & 0.03 \\
\hline Waist circumference $(\mathrm{cm})$ & 1.01 & $1.00-1.03$ & 0.02 \\
\hline Sugar $(\mathrm{mg} / \mathrm{dL})$ & 1.00 & $0.99-1.01$ & 0.17 \\
\hline $\mathrm{DBP}(\mathrm{mm} \mathrm{Hg})$ & 1.00 & $0.99-1.01$ & 0.43 \\
\hline Total cholesterol (mg/dL) & 1.01 & $1.00-1.02$ & 0.002 \\
\hline HDL-C (mg/dL) & 1.00 & $0.99-1.01$ & 0.47 \\
\hline Uric acid (mg/dL) & 0.93 & $0.88-0.98$ & 0.004 \\
\hline Smoke (yes vs. no) & 1.06 & $0.86-1.25$ & 0.68 \\
\hline Alcohol drinking (yes vs. no) & 1.13 & $0.85-1.40$ & 0.49 \\
\hline Betel nut (yes vs. no) & 1.01 & $0.55-1.48$ & 0.68 \\
\hline Milk (yes vs. no) & 0.98 & $0.82-1.14$ & 0.68 \\
\hline Meat (yes vs. no) & 1.23 & $1.04-1.49$ & 0.02 \\
\hline \multicolumn{4}{|l|}{ Osteoporosis versus normal } \\
\hline Age (year) & 1.07 & $1.06-1.09$ & $<0.001$ \\
\hline Height $(\mathrm{cm})$ & 0.98 & $0.97-0.99$ & 0.005 \\
\hline Weight $(\mathrm{kg})$ & 0.97 & $0.95-0.99$ & $<0.001$ \\
\hline Waist circumference $(\mathrm{cm})$ & 1.02 & $1.00-1.03$ & 0.02 \\
\hline Sugar (mg/dL) & 1.00 & $0.99-1.01$ & 0.12 \\
\hline $\mathrm{DBP}(\mathrm{mm} \mathrm{Hg})$ & 1.00 & $0.99-1.01$ & 0.96 \\
\hline Total cholesterol (mg/dL) & 1.01 & $1.00-1.02$ & 0.003 \\
\hline HDL-C (mg/dL) & 1.01 & $0.99-1.02$ & 0.10 \\
\hline Uric acid (mg/dL) & 0.90 & $0.85-0.95$ & $<0.001$ \\
\hline Smoke (yes vs. no) & 1.22 & $0.97-1.46$ & 0.09 \\
\hline Alcohol drinking (yes vs. no) & 1.15 & $0.84-1.46$ & 0.48 \\
\hline Betel nut (yes vs. no) & 1.32 & $0.60-2.05$ & 0.75 \\
\hline Milk (yes vs. no) & 0.95 & $0.78-1.11$ & 0.43 \\
\hline Meat (yes vs. no) & 1.47 & $1.19-1.75$ & $<0.001$ \\
\hline
\end{tabular}

(odds ratio $[\mathrm{OR}]=1.03,95 \%$ confidence interval $[C I]$ : $1.01-1.04)$, weight $(\mathrm{OR}=0.98,95 \%$ CI: 0.97-1.00), waist circumference $(\mathrm{OR}=1.01$, 95\% CI: $1.00-1.03)$, total cholesterol $(\mathrm{OR}=1.01$, 95\% CI: $1.00-1.02)$, uric acid $(\mathrm{OR}=0.93,95 \%$
CI: 0.88-0.98), and regular habits of meat intake (OR=1.23, 95\% CI: 1.04-1.49) appeared to be statistically significantly related to osteopenia. Age $(\mathrm{OR}=1.07,95 \% \mathrm{CI}: 1.06-1.09)$, height $(\mathrm{OR}=0.98,95 \% \mathrm{CI}: 0.97-0.99)$, weight 
$(\mathrm{OR}=0.97,95 \% \mathrm{CI}: 0.95-0.99)$, waist circumference (OR $=1.02,95 \% \mathrm{CI}: 1.00-1.03)$, total cholesterol $(\mathrm{OR}=1.01,95 \% \mathrm{CI}: 1.00-1.02)$, uric acid $(\mathrm{OR}=0.90,95 \% \mathrm{CI}: 0.85-0.95)$, and regular habits of meat intake (OR=1.47, 95\% CI: 1.29-1.75) appeared to be statistically significantly related to osteoporosis.

\section{DISCUSSION}

Table 4 presents the prevalence of osteopenia and osteoporosis in various types of study populations. ${ }^{17-21}$ The prevalence of osteoporosis ranges from 19.5 to $34.5 \%$, and the prevalence of osteopenia ranges from 37.8 to $51.6 \%$. There is only a subtle difference between the prevalence of osteoporosis and osteopenia in our research when compared with other studies. In addition to diagnostic criteria, this disparity is largely due to the different sources of study subjects.

Age is a well-known risk factor for osteoporosis. An elderly person has a greater probability of having osteopenia and osteoporosis as bone mass decreases with age, that is, osteoporosis can be considered an aging process. ${ }^{22}$ As a result, old age could be a predictor of high osteoporosis probability clinically.

Height is recognized as one of the risk factors for osteoporosis in several types of research. ${ }^{23-27}$ In our analysis, the results revealed that the average height of the patients with osteoporosis was significantly lower than the non-osteoporosis group. Compared with other research in which the study group focused on people of middle age, high body height is the risk factor for osteoporosis. ${ }^{28,29}$ The height loss is common in the elderly population. The occurrence of height loss is owing to the curvature of the spine, narrowing of intervertebral discs, and vertebral fractures. ${ }^{30}$ However, further studies with larger sample sizes are needed to confirm this interference.

Total cholesterol concentration is linked to some diseases. It can lead to cardiovascular diseases. It is injurious to bone structure and is

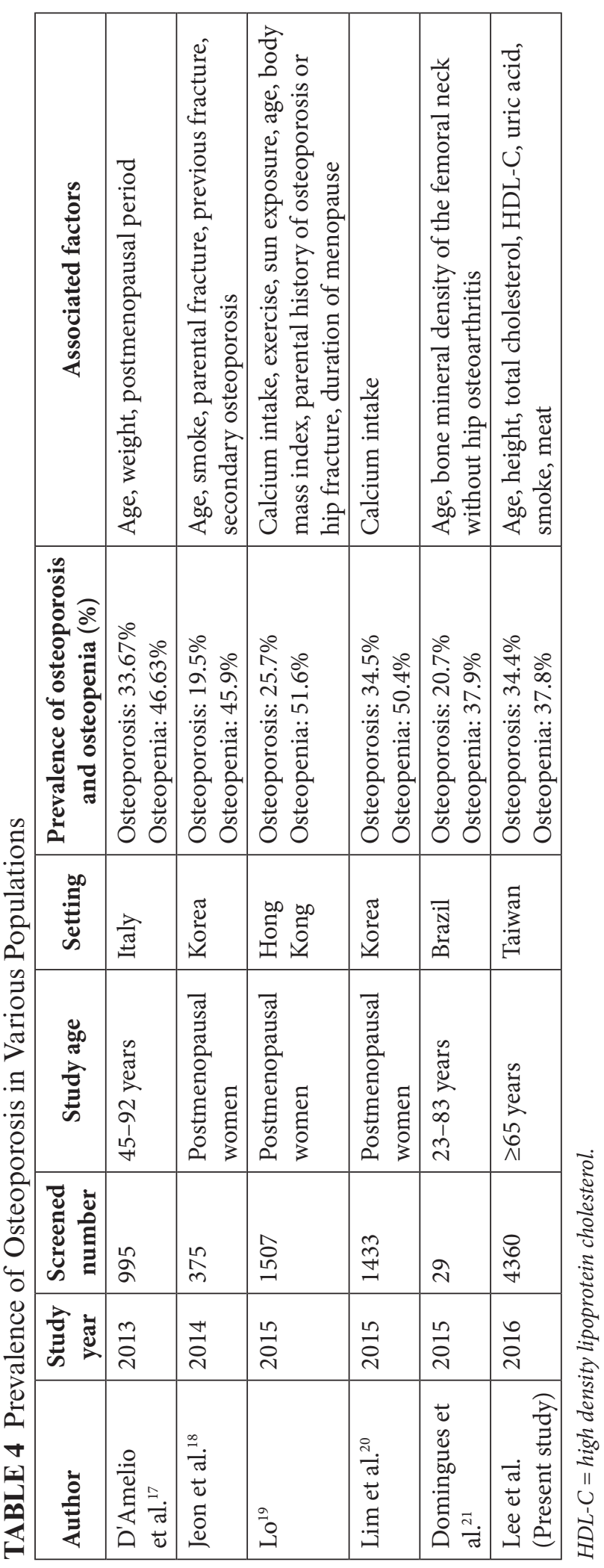

J Mens Health Vol 16(1):e53-e62; 19 March 2020

This article is distributed under the terms of the Creative Commons Attribution-Non

Commercial 4.0 International License. @2020 Chin-Yu Lee et al. 
correlated with bone turnover, which may predict osteoporosis. $^{31,32}$ In this study, higher total cholesterol concentration is proven to be related to the high prevalence of osteopenia and osteoporosis. In addition, HDL-C is widely regarded as good cholesterol because it protects against the development of atherosclerosis disease. ${ }^{33}$ However, when it comes to the relevance to osteoporosis, it yielded conflicting results. Some paper did not observe the association between HDL-C and osteoporosis, ${ }^{34}$ but some researches revealed that elevated levels of serum HDL-C had a higher probability of forming osteoporosis than the low HDL-C levels in Chinese postmenopausal women. ${ }^{35}$ In this study, the association between HDL-C, osteoporosis, and osteopenia is statistically significant.

Uric acid is the end product of purine metabolism. When the intake of purines increases or the body has problems in metabolism, high level of serum uric acid may lead to gout. However, it is a protective factor for osteopenia and osteoporosis. The results in this study showed that higher uric acid levels were linearly associated with higher lumbar spine BMD, and it is protective for bone loss in peri- and postmenopausal women. ${ }^{8,36}$ The possible reason may be due to the antioxidant ability of uric acid. Nevertheless, the mechanism of the association between uric acid and BMD still needs clarification.

Smoking habits showed only a borderline significance to osteoporosis in this study. Previous studies indicated that smoking could lead to DNA damage and oxidative stress, further leading to many diseases such as various cancers and cardiovascular diseases. ${ }^{37,38}$ Likewise, smoking inhibits bone formation and increases bone resorption, which decreases BMD and causes

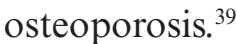

After adjustment for confounding factors, our findings suggest that regular meat intakeis one of the risk factors of osteoporosis. Daily intake also has a great impact on the bone density. ${ }^{40}$ Meat is considered an important component of a balanced diet, and it helps in body growth as it contains nutrients, such as protein, fatty acid, iron, vitamin $\mathrm{B}$, and zinc. ${ }^{41}$ As for the interaction between meat intake and osteoporosis, the results are not all positive. Some research observe less frequent prevalence of osteoporosis in Chinese postmenopausal women preferring meat food habits. ${ }^{42}$ Some conclude that having a large proportion of animal meat has the possibility to cause adverse effects on bone metabolism.

\section{Methodological Considerations}

An important major inadequacy in this study was the possible range bias due to only one agingpopulace curtained in Taiwan. The prospective influence on the frequency estimated and the study-observed osteoporosis and osteopeniaconnected threat aspects was unavoidable.Given the relative big model scope, nevertheless, we still retained enough numerical control to evaluate efficiently the existence of any sex dissimilarities between the numerous accompanying threat aspects of osteoporosis successive to alteration for difficult dynamics. Furthermore, we would not be able to reflect long-term exposure to various demographic or biochemical aspects or factors as our measurements were conducted only at a single point in time and, by clear inference, which might be an important influencer of osteoporosis. Finally, with our study design, it was difficult to determine the effects of changes in biochemical levels over time after the development of osteoporosis. By conducting a number of prospective longitudinal analogous studies, the solution to such a quandary could best be accomplished, and the results would also complement the cross-sectional findings of this study.

\section{CONCLUSION}

Numerous medical influences independently were designated affecting the commonness of osteoporosis in aging among the fishing and 
agricultural populace. Further studies are needed not only to evaluate the temporal sequence of events that typically lead to osteoporosis but also to assess how gender-related differences are related to osteoporosis among the elderly population.

\section{ACKNOWLEDGMENTS}

This study was selected for poster presentation at the World Congress on Osteoporosis, Osteoarthritis and Musculoskeletal Diseases April 14-17, 2016, Malaga, Spain.

\section{CONFLICTS OF INTEREST}

The authors have no proprietary interest in any aspect of this study. The authors certify that, within the past 5 years and in the foreseeable future, all affiliations or financial involvement with any organization or entity with a financial interest in, or financial conflict with, the subject matter or materials discussed in this manuscript are fully disclosed (e.g. employment, consultancies, honoraria, stock ownership or options, expert testimony, grants or patents received or pending, and royalties).

\section{FUNDING}

There was no additional financial support from any public or private sources to conduct this study.

\section{REFERENCES}

1. Liu BX, Chen SP, Li YD, et al. The effect of the modified eighth section of eight-section brocade on osteoporosis in postmenopausal women: a prospective randomized trial. Medicine 2015;94:e991. https://doi.org/10.1097/MD.00000 00000000991

2. Pisani P, Renna MD, Conversano F, et al. Major osteoporotic fragility fractures: risk factor updates and societal impact. World J Orthop 2016;7:171-81. https://doi.org/10.5312/wjo.v7.i3.171

3. Berry SD, McLean RR, Hannan MT, et al. Changes in bone mineral density (BMD) may predict the risk of fracture differently in older adults according to fall history. J Am Geriatr Soc 2014;62:2345-9. https://doi.org/10.1111/jgs. 13127

4. Darbà J, Kaskens L, Pérez-Álvarez N, et al. Disability-adjusted-life-years losses in postmenopausal women with osteoporosis: a burden of illness study. BMC Public Health 2015;15:324. https://doi.org/10.1186/s12889-015-1684-7

5. Mettyas T, Carpenter C. Secondary prevention of osteoporosis in non-neck of femur fragility fractures: is it value for money? A retrospective, prospective and cross-sectional cohort study. J Orthop Surg Res 2013;8:44. https://doi.org/ 10.1186/1749-799X-8-44

6. Ferencz V, Horváth CS, Huszár S, et al. Evaluation of risk factors for fractures in postmenopausal women with osteoporosis. Orv Hetil 2015;156: 146-53. https://doi.org/10.1556/OH.2015.30088

7. Finkenstedt G, Skrabal F, Gasser RW, et al. Lactose absorption, milk consumption, and fasting blood glucose concentrations in women with idiopathic osteoporosis. Br Med J (Clin Res Ed) 1986;292:161-2. https://doi.org/10.1136/bmj.292. 6514.161

8. Ishii S, Miyao M, Mizuno Y, et al. Association between serum uric acid and lumbar spine bone mineral density in peri- and postmenopausal Japanese women. Osteoporos Int 2014;25:1099-105. https://doi.org/10.1007/s00198-013-2571-7

9. Nabipour I, Sambrook PN, Blyth FM, et al. Serum uric acid is associated with bone health in older men: a cross-sectional population-based study. J Bone Miner Res 2011;26:955-64. https:// doi.org/10.1002/jbmr.286

10. Waugh EJ, Lam MA, Hawker GA, et al. Risk factors for low bone mass in healthy 40-60 year old women: a systematic review of the literature. Osteoporos Int 2009;20:1-21. https://doi.org/ 10.1007/s00198-008-0643-x

11. Shin S, Joung H. A dairy and fruit dietary pattern is associated with a reduced likelihood of osteoporosis in Korean postmenopausal women. $\mathrm{Br} \mathbf{J}$ Nutr 2013;110:1926-33. https://doi.org/10.1017/ S0007114513001219

12. Baron JA, Farahmand BY, Weiderpass E, et al. Cigarette smoking, alcohol consumption, and risk of hip fracture in women. Arch Intern Med 
2001;161:983-8. https://doi.org/10.1001/archinte. 161.7 .983

13. Kanis JA, McCloskey EV, Johansson H, et al. European guidance for the diagnosis and management of osteoporosis in postmenopausal women. Osteoporos Int 2013;24:23-57. https:// doi.org/10.1007/s00198-012-2074-y

14. Jang SY, Kim IH, Ju EY, et al. Chronic kidney disease and metabolic syndrome in a general Korean population: the Third Korea National Health and Nutrition Examination Survey (KNHANES III) Study. J Public Health 2010;32:538-46. https://doi. org/10.1093/pubmed/fdp127

15. Grundy SM, Cleeman JI, Daniels SE, et al. Diagnosis and management of the metabolic syndrome: an American Heart Association/ National Heart, Lung, and Blood Institute Scientific Statement. Circulation 2005;112:273552. https://doi.org/10.1161/CIRCULATIONAHA. 105.169404

16. Chan YH. Multinomial logistic regression. Singapore Med J 2005;46:259-69.

17. D'Amelio P, Spertino E, Martino F, et al. Prevalence of postmenopausal osteoporosis in Italy and validation of decision rules for referring women for bone densitometry. Calcif Tissue Int 2013;92:437-43. https://doi.org/10.1007/s00223013-9699-5

18. Jeon YJ, Kim JW, Park JS. Factors associated with the treatment of osteoporosis in Korean postmenopausal women. Women Health 2014;54: 48-60. https://doi.org/10.1080/03630242.2013. 862896

19. Lo SS. Bone health status of postmenopausal Chinese women. Hong Kong Med J 2015;21: 536-41. https://doi.org/10.12809/hkmj154527

20. Lim YS, Lee SW, Tserendejid Z, et al. Prevalence of osteoporosis according to nutrient and food group intake levels in Korean postmenopausal women: using the 2010 Korea National Health and Nutrition Examination Survey Data. Nutr Res Pract 2015;9:539-46. https://doi.org/10.4162/ nrp.2015.9.5.539

21. Domingues VR, de Campos GC, Plapler PG, et al. Prevalence of osteoporosis in patients awaiting total hip arthroplasty. Acta Ortop Bras
2015;23:34-7. https://doi.org/10.1590/1413-7852 2015230100981

22. Riggs BL, Wahner HW, Dunn WL, et al. Differential changes in bone mineral density of the appendicular and axial skeleton with aging: relationship to spinal osteoporosis. J Clin Invest 1981;67:328-35. https://doi.org/10.1172/JCI 110039

23. Siminoski K, Jiang G, Adachi JD, et al. Accuracy of height loss during prospective monitoring for detection of incident vertebral fractures. Osteoporos Int 2005;16:403-10. https://doi.org/10.1007/ s00198-004-1709-z

24. Siminoski K, Warshawski RS, Jen H, et al. The accuracy of historical height loss for the detection of vertebral fractures in postmenopausal women. Osteoporos Int 2006;17:290-6. https://doi.org/ 10.1007/s00198-005-2017-y

25. Bennani L, Allali F, Rostom S, et al. Relationship between historical height loss and vertebral fractures in postmenopausal women. Clin Rheumatol 2009;28:1283-9. https://doi.org/10.1007/s10067009-1236-6

26. Yeoum SG, Lee JH. Usefulness of estimated height loss for detection of osteoporosis in women. J Korean Acad Nurs 2011;41:758-67. https://doi. org/10.4040/jkan.2011.41.6.758

27. Krege JH, Kendler D, Krohn K, et al. Relationship between vertebral fracture burden, height loss, and pulmonary function in postmenopausal women with osteoporosis. J Clin Densitom 2015;18:506-11. https://doi.org/10.1016/j.jocd.2015.02.004

28. Joakimsen RM, Fønnebø V, Magnus JH, et al. The Tromsø Study: body height, body mass index and fractures. Osteoporos Int 1998;8:436-42. https://doi.org/10.1007/s001980050088

29. Meyer HE, Tverdal A, Falch JA. Body height, body mass index, and fatal hip fractures: 16 years' follow-up of 674,000 Norwegian women and men. Epidemiology 1995;6:299-305. https://doi. org/10.1097/00001648-199505000-00019

30. Briot K, Legrand E, Pouchain D, et al. Accuracy of patient-reported height loss and risk factors for height loss among postmenopausal women. CMAJ 2010;182:558-62. https://doi.org/10.1503/ cmaj.090710 
31. Yamauchi M, Yamaguchi $T$, Nawata $K$, et al. Increased low-density lipoprotein cholesterol level is associated with non-vertebral fractures in postmenopausal women. Endocrine 2015;48:279-86. https://doi.org/10.1007/s12020-014-0292-0

32. Jeong TD, Lee W, Choi SE, et al. Relationship between serum total cholesterol level and serum biochemical bone turnover markers in healthy pre- and postmenopausal women. Biomed Res Int 2014;2014:398397. https://doi.org/10.1155/2014/ 398397

33. Toth PP, Barylski M, Nikolic D, et al. Should low high-density lipoprotein cholesterol (HDL-C) be treated? Best Pract Res Clin Endocrinol Metab 2014;28:353-68. https://doi.org/10.1016/j.beem. 2013.11.002

34. Pliatsika P, Antoniou A, Alexandrou A, et al. Serum lipid levels and bone mineral density in Greek postmenopausal women. Gynecol Endocrinol 2012;28:655-60. https://doi.org/10.3109/0951359 0.2011 .650766

35. Li S, Guo H, Liu Y, et al. Relationships of serum lipid profiles and bone mineral density in postmenopausal Chinese women. Clin Endocrinol (Oxf) 2015;82:53-8. https://doi.org/10.1111/cen.12616

36. Makovey J, Macara M, Chen JS, et al. Serum uric acid plays a protective role for bone loss in periand postmenopausal women: a longitudinal study. Bone 2013;52:400-6. https://doi.org/10.1016/j. bone.2012.10.025
37. Ganapathy V, Ramachandran I, Rubenstein DA, et al. Detection of in vivo DNA damage induced by very low doses of mainstream and sidestream smoke extracts using a novel assay. Am J Prev Med 2015;48(1 Suppl 1):S102-10. https://doi. org/10.1016/j.amepre.2014.08.017

38. Kunchithapautham K, Atkinson C, Rohrer B. Smoke exposure causes endoplasmic reticulum stress and lipid accumulation in retinal pigment epithelium through oxidative stress and complement activation. J Biol Chem 2014;289:14534-46. https://doi.org/10.1074/jbc.M114.564674

39. Gao SG, Li KH, Xu M, et al. Bone turnover in passive smoking female rat: relationships to change in bone mineral density. BMC Musculoskelet Disord 2011;12:131. https://doi.org/10.1186/14712474-12-131

40. Tucker KL, Chen H, Hannan MT, et al. Bone mineral density and dietary patterns in older adults: the Framingham Osteoporosis Study. Am J Clin Nutr 2002;76:245-52. https://doi.org/10.1093/ajcn/ 76.1.245

41. Pereira PM, Vicente AF. Meat nutritional composition and nutritive role in the human diet. Meat Sci 2013;93:586-92. https://doi.org/10.1016/j. meatsci.2012.09.018

42. Qing GZ, Lu Y, Yi T, et al. The relationship of frequency of meat consumption and osteoporosis in Chinese postmenopausal women. Int J Clin Exp Med 2015;8:21130-7. 